\title{
Legalidade e Eficácia Jurídica dos Títulos de Pós-Graduação Stricto Sensu - Mestrado e/ou Doutorado - Originários dos Estados Partes do Mercosul, na Jurisdição Brasileira
}

\section{Legality and effectiveness of post-graduate studies - Master and/or doctorate- originated from the States that integrates Mercosul, in the Brazilian Jurisdiction}

\author{
Marcos Machado ${ }^{1}$ \\ Mario Arthur de Souza Fontes ${ }^{2}$ \\ Dario Aragão Neto ${ }^{3}$
}

Palavras-chave:

MERCOSUL

Direito

Validade

Eficácia

Título acadêmico

\section{Resumo:}

$\mathrm{O}$ artigo se destina à área de ciências humanas e sociais aplicadas, em especial ao direito e tem por objetivo propiciar aos leitores, uma visão macro da legalidade e eficácia jurídica dos títulos de pós-graduação stricto sensu (mestrado e/ou doutorado) originários dos Estados Partes que compõem o MERCOSUL, no contexto da jurisdição brasileira, apontando vertentes jurídicas positivas e negativas sobre o tema, esculpidas pelo nosso ordenamento jurídico interno. A metodologia utilizada na pesquisa é do tipo documental (particulares e/ou públicos) de procedimento reflexivo, sistemático, com abordagem descritiva e exploratória. Sua fundamentação teórica esta amparada no ordenamento jurídico nacional em vigor (constitucional e infraconstitucional). Os resultados esperados são de promover uma reflexão jurídica a respeito dessa questão, por se tratar de um tema controverso que envolve nações com diferentes características sócioeconômicas, mas que têm um objetivo comum: promover a integração e a união dos seus povos, buscando o fortalecimento da América Latina.

\section{Abstract}

This article is intended for human and social applied sciences, specially to Law and it aims to provide the readers a macro view of the legality and effectiveness of the strict sensu post-graduate titles (master and/ or doctorate) originated from the states that integrates Mercosul in the Brazilian Jurisdiction context, pointing out positive and negative legal aspects about the topic carved in our internal legal order. The methodology used in this research is the documental type (private and/ or public)using reflexive and systematic procedure, in a descriptive and exploratory approach. Its theory is based on the current national legal aspects (constitutional and infra constitutional). The expected results are to promote a legal reflection about this question, due to be a controversial topic that involves nations of different social economical characteristics, but with a common aim: promote the integration and unity of their people, searching the Latin America strength.
Key words:

\section{MERCOSUL}

Law

Validity

Effectiveness

Academic title
Artigo
Original

Original

Paper

Recebido em 09/2011

Aprovado em 12/2011

' Doutorando em Direito, Mestrado em Direito, Mestrando em Gestão e Desenvolvimento Regional, Professor UniFOA;

${ }^{2}$ Engenheiro e Professor Universitário; Mestrado em Engenharia Civil, Especialização em Docência Superior,Professor UniFOA;

${ }^{3}$ Doutorando em Direito, Mestrado em Ensino em Ciências da Saúde e do Meio Ambiente, Professor UniFOA. 
O MERCOSUL - Mercado Comum do Sul ${ }^{1}$ foi criado em 26 de março de 1991, através do Tratado de Assunção, tendo como países integrantes Argentina, Brasil, Paraguai e Uruguai.

Em sentido mais amplo, o Mercado Comum do Sul tem como escopo fortalecer os vínculos sócioculturais entre seus povos, sustentando a integração econômica regional e, através dessa, constituir uma via para que os países da América Latina possam acelerar seu processo de desenvolvimento econômico e social de forma integrada.

Com o intuito de mitigar os entraves comerciais e as diferenças sócioeconômicas e culturais de cada nação, os países membros perceberam a necessidade de estabelecerem instrumentos jurídicos que orientassem a definição de políticas e estratégias comuns. Essa é a única forma de garantir o nível desejado de integração entre os Estados membros e fomentar uma integração direta na área acadêmica e científica, já que há a preocupação em assegurar um tratamento especial para os países de menor desenvolvimento econômico relativo. Impulsionando vínculos de solidariedade e cooperação na América Latina, o MERCOSUL visa promover um processo de fortalecimento convergente que conduza ao estabelecimento de um mercado comum regional efetivo.

Dentro dessa política, não poderiam ficar ausentes decisões acerca do desenvolvimento e intercâmbio na área educacional e de pesquisa mercosulenses. Surgiu então, de forma imperiosa, a necessidade de se estabelecer regras que orientassem a definição de políticas e estratégias comuns para o desenvolvimento desse intercâmbio. Então, se chegou à aprovação do Protocolo de Admissão de Títulos e Graus Universitários para o Exercício de Atividades Acadêmicas nos Estados Partes do Mercosul $^{2}$, em 1997, e ao efetivo Acordo Internacional $^{3}$ de mesmo nome, em 1999. Ambos os documentos contêm dispositivos que têm por finalidade propiciar aos docentes e pesquisadores, uma ferramenta de apoio e intercâmbio de uma melhor formação, capacitação científica, tecnológica e cultural, entre os Países Membros e em prol da modernização dos Estados Partes.

Como forma de integrar a academia científica, uma das premissas estabelecidas no aludido Acordo é o mútuo reconhecimento automático dos títulos de pós-graduação stricto sensu, originários dos Estados Partes do MERCOSUL, para fins acadêmicos. Esse dispositivo consta no Acordo firmado pelos países do Mercosul e no ordenamento jurídico pátrio que regulou essa matéria, como se verá adiante, razão pela qual sua validação de forma automática está garantida por lei.

A discussão repousa justamente na questão acerca da validação automática dos diplomas acadêmicos obtidos na Argentina, Paraguai e Uruguai pelos brasileiros. Hoje, na maioria dos casos, os brasileiros são obrigados a promover o processo de revalidação nas universidades brasileiras, muito embora entendamos que não há dispositivo legal que os obrigue a proceder dessa forma.

A legislação ratifica o Acordo e garante ao detentor desses títulos acadêmicos o direito de terem seus diplomas reconhecidos automaticamente no país. Porém, como veremos mais detalhadamente, o Acordo e a legislação promulgada aqui no Brasil que o endossou na íntegra, não vem sendo respeitados pelos atores da administração pública e as decisões dos Tribunais ainda não são uníssonas sobre o tema, o que vem tornando o processo de reconhecimento automático daqueles títulos juridicamente confuso e até mesmo inviável.

Assim, nosso eixo textual pretende equacionar os aspectos mais pertinentes do assunto, tentando trazer uma compreensão da situação jurídica atual desse impasse, através das seguintes fases cognitivas jurídicas: a primeira tem o aspecto de propiciar aos leitores uma holística do direito positivo em relação

${ }^{1}$ O MERCOSUL surgiu oficialmente em 26 de março de 1991, com a assinatura do Tratado de Assunção pelos seguintes países: República Argentina, República Federativa do Brasil, República do Paraguai e a República Oriental do Uruguai, tendo como objetivo básico, a criação do Mercado Comum do Sul - MERCOSUL. Disponível em http://www.mercosul.gov.br/.

${ }^{2}$ Protocolo de Admissão de Títulos e Graus Universitários para o Exercício de Atividades Acadêmicas nos Estados Partes do Mercosul. Disponível em http://www.mercosur.int/msweb/Normas/normas_web/Decisiones/PT/Dec_003_097_Prot\%20Adm\%20T\%C3\%ADt\%20 Graus\%20Univers\%20Ativ\%20Academicas_Ata\%201_97.PDF.

${ }^{3}$ Acordo de Admissão de Títulos e Graus Universitários para o Exercício de Atividades Acadêmicas nos Estados Partes do Mercosul. http:// www2.mre.gov.br/dai/m_3415.htm 
ao MERCOSUL; a segunda, apresentar e estabelecer os enquadramentos jurídicos de normatização sobre o tema proposto; terceira, de aferir a questão de ordem pública interna e por fim, a quarta e última fase, de apontar os pontos convergentes e divergentes em relação à validação ou não dos diplomas.

\section{MERCOSUL: Uma holística positivada de sua trajetória}

O MERCSUL nasceu da necessidade de contribuição à obtenção de um novo esquema de cooperação horizontal entre países em desenvolvimento e suas áreas de integração, inspirado nos princípios do direito internacional em matéria de desenvolvimento social e de comércio.

Os Estados Partes do MERCOSUL se atentaram à realidade factual das convergências econômicas e à necessidade de políticas direcionadas que visassem o desenvolvimento econômico e sustentável do bloco e para tanto, priorizaram alguns dispositivos comerciais: agilização dos trâmites nas fronteiras, convergência da tarifa externa comum e eliminação de sua dupla cobrança, adoção de critérios para a distribuição da renda aduaneira, para o fortalecimento institucional, bem como o melhoramento das relações externas com outros blocos ou países.

Embora criado em 1991, os esforços por um mercado comum no cone sul constituíam um antigo sonho entre as nações sul americanas, nascido já na década de 60 com a criação da Associação Latino-Americana de Livre Comércio (ALALC). Mais tarde, nos anos 80, Brasil e Argentina assinaram vários acordos comerciais com o objetivo de uma maior integração socioeconômica, em especial o Tratado de Montevidéu, uma espécie de esboço do viria a ser o Mercosul no futuro.

Desde a assinatura do Tratado, o Brasil, assim com os demais países, já mantinha a posição de adotar as regras de tais instrumentos protocolares e, após a sua assinatura, a respectiva ratificação dos mesmos através do nosso ordenamento jurídico. No caso Tratado de Montevidéu, pelo Decreto Legislativo $n^{\circ}$. 66, de 16 de novembro de $1981^{4}$, e posteriormente pelo Decreto Presidencial n ${ }^{\circ}$. 87.054, de 23 de março de $1982^{5}$. Por consequência, nosso ordenamento jurídico passou a adotar os seguintes objetivos, funções e princípios:

Tratado de Montevidéu

Agosto de 1980.

\section{CAPÍTULO I}

\section{Objetivos, funções e princípios}

Artigo $\mathbf{1}^{\circ}$ - Pelo presente Tratado, as Partes Contratantes dão prosseguimento ao processo de integração encaminhado a promover o desenvolvimento econômico-social, harmônico e equilibrado, da região e, para esse efeito, instituem a Associação Latino-Americana de Integração (doravante denominada "Associação"), cuja sede é a cidade de Montevidéu, República Oriental do Uruguai. Esse processo terá como objetivo a longo prazo o estabelecimento, em forma gradual e progressiva, de um mercado comum latino-americano.

Artigo $\mathbf{2}^{\mathbf{0}}$ - As normas e mecanismos do presente Tratado, bem como aqueles que em seu âmbito estabeleçam os países membros, terão por objetivo o desenvolvimento das seguintes funções básicas da Associação: a promoção e regulação do comércio recíproco, a complementação econômica e o desenvolvimento das ações de cooperação econômica que coadjuvem a ampliação dos mercados.

Artigo $3^{\circ}$ - Na aplicação do presente Tratado e na evolução para seu objetivo final, os países membros levarão em conta os seguintes princípios:

\footnotetext{
${ }^{4}$ BRASIL. Decreto Legislativo $n^{\circ} .66$, de 16 de novembro de 1981. Aprova o texto do Tratado de Montevidéu 1980, firmado pelos Plenipotenciários dos Governos da República Federativa do Brasil, da República Argentina, da República da Bolívia, da República da Colômbia, da República do Chile, da República do Equador, dos Estados Unidos Mexicanos, da República do Paraguai, da República do Peru, da República Oriental do Uruguai, e da República da Venezuela, a 12 de agosto de 1980. Disponível em: < http://www.diariodasleis.com.br/ busca/exibelink.php?numlink=1-98-17-1981-11-16-66>. Acesso em: 21 nov. 2011.

Decreto Presidencial no ${ }^{\circ}$ 87.054, de 23 de março de 1982. Promulga o Tratado de Montevidéu 1980. Disponível em: <http://www2 mre.gov.br/dai/m_87054_1980.htm>. Acesso em: 21 nov. 2011 .
} 
a) Pluralismo, sustentado na vontade dos países membros para sua integração, acima da diversidade que em matéria política e econômica possa existir na região;

b) Convergência, que se traduz na multilateralização progressiva dos acordos de alcance parcial, através de negociações periódicas entre os países-membros, em função do estabelecimento do mercado comum latino-americano;

c) Flexibilidade, caracterizada pela capacidade para permitir a celebração de acordos de alcance parcial, regulada com forma compatível com a consecução progressiva de sua convergência e pelo fortalecimento dos vínculos de integração;

d) Tratamentos diferenciais, estabelecidos na forma que em cada caso se determine, tanto nos mecanismos de alcance regional como nos de alcance parcial, com base em três categorias de países, que se integrarão levando em conta suas características econômico estruturais. Esses tratamentos serão aplicados em determinada magnitude aos países de desenvolvimento médio e de maneira mais favorável aos países de menor desenvolvimento econômico relativo; e

e) Múltiplo, para possibilitar distintas formas de ajustes entre os países membros, em harmonia com os objetivos e funções do processo de integração, utilizando todos os instrumentos capazes de dinamizar e ampliar os mercados a nível regional.

Os quatro Estados Partes (países) que constituem o MERCOSUL, têm por objetivo primordial, o fortalecimento e a integração mútua das nações integrantes, através da livre circulação de bens, serviços e fatores produtivos, estabelecendo uma tarifa externa comum (TEC), além da criação de políticas comerciais integradas que visassem o crescimento macroeconômico e setorial.

No entanto, via de consequência e como pressuposto ao seu sucesso econômico, partindo do princípio de que uma economia não pode prosperar sem uma base de leis que a alicerce, imperiosa se tornou a necessidade de uma conciliação do direito positivo de cada Estado Parte em prol de interesses do Bloco. É o que dispõe a parte final do artigo $1^{\circ}$ do citado Tratado, aqui in verbis:

Artigo $1^{0}$ :

Os Estados Partes decidem constituir um Mercado Comum, que deverá estar estabelecido a 31 de dezembro de 1994, e que se denominará "Mercado Comum do Sul" (MERCOSUL). Este Mercado Comum implica:

A livre circulação de bens serviços e fatores produtivos entre os países, através, entre outros, da eliminação dos direitos alfandegários restrições não tarifárias à circulação de mercado de qualquer outra medida de efeito equivalente;

O estabelecimento de uma tarifa externa comum e a adoção de uma política comercial comum em relação a terceiros Estados ou agrupamentos de Estados e a coordenação de posições em foros econômico-comerciais regionais e internacionais;

A coordenação de políticas macroeconômicas e setoriais entre os Estados Partes - de comércio exterior, agrícola, industrial, fiscal, monetária, cambial e de capitais, de serviços, alfandegária, de transportes e comunicações e outras que se acordem -, a fim de assegurar condições adequadas de concorrência entre os Estados Partes; e

O compromisso dos Estados Partes de harmonizar suas legislacões, nas áreas pertinentes, para lograr o fortalecimento do processo de integracão. (grifo nosso) 
Assim, os Estados participantes se comprometeram no sentido de unir os esforços de integração e cooperação mútua, surgindo, então, para sua operabilidade efetiva, a necessidade de se buscar um entendimento jurídico uniforme, de validez e eficácia acerca dos documentos expedidos por seus governos. E essa uniformidade jurídica, é que se torna essencial ao bom cumprimento das regras que regem as relações internacionais de um Estado.

\section{Normatização do MERCOSUL:} Efeitos jurídicos do Acordo de Admissão de Títulos e Graus Universitários para o Exercício de Atividades Acadêmicas nos Estados Partes do MERCOSUL

A estrutura normativa do MERCOSUL está alicerçada nos seguintes pilares do direito positivo: decisões; resoluções; diretrizes; recomendações, tratados, protocolos e acordos, dentre outros. Muito embora cada Estado Parte tenha sua própria estrutura normatizada e ordenamento jurídico próprio, o Tratado Internacional, para que tenha plenitude de eficácia, necessita que seja integrado em cada um dos ordenamentos jurídicos dos países que $o$ aderem. Assim, uma vez ocorrida a efetividade da integração de Tratado Internacional no conjunto positivado jurídico de cada país, o mesmo passa a ter força de norma jurídica nacional naquele país signatário.

A Convenção de Viena ${ }^{6}$ sobre o direito dos Tratados, que passou a vigorar a partir de 27 de janeiro de 1980, definiu os parâmetros conceituais de "tratado", que significa em "consistir em um acordo internacional concluído por escrito entre Estados e regido pelo Direito Internacional, quer conste de um instrumento único, quer de dois ou mais instrumentos conexos, qualquer que seja sua denominação específica".

O teor do Acordo assinado em 1999 é cristalino e já na sua introdução demonstra a necessidade pungente do reconhecimento dos títulos internacionais para fins acadêmicos, com o fito de criar uma plataforma equânime no campo científico internacional do cone sul.
Por essa razão, assinala a necessidade de se normatizar esse intercâmbio de reconhecimento de títulos através da legislação de cada Estado Parte, o que também ficou previsto no artigo terceiro do instrumento, conforme a seguir exposto:

ACORDO DE ADMISSÃO DE TÍTULOS E GRAUS UNIVERSITÁRIOS PARA O EXERCÍCIO E ATIVIDADES ACADÊMICAS NOS ESTADOS PARTES DO MERCOSUL

Os Governos da República da Argentina,
da República Federativa do Brasil, da
República do Paraguai e da República
Oriental do Uruguai, a seguir denomi-
nados "Estados Partes", em virtude dos
princípios, fins e objetivos do Tratado de
Assunção, assinado em março de 1991,

\section{CONSIDERANDO:}

Que a educação tem papel central para que o processo de integração regional se consolide;

Que a promoção do desenvolvimento harmônico da Região, nos campos científico e tecnológico, é fundamental para responder aos desafios impostos pela nova realidade sócioeconômica do continente;

Que o intercâmbio de acadêmicos entre as instituições de ensino superior da Região apresenta-se como mecanismo eficaz para a melhoria da formação e da capacitação científica, tecnológica e cultural e para a modernização dos Estados Partes;

Que da ata da X Reunião de Ministros da Educação dos Países Signatários do Tratado do Mercado Comum do Sul, realizada em Buenos Aires, Argentina, no dia vinte de junho de mil novecentos e noventa e seis, constou a recomendação de que se preparasse um Protocolo sobre a admissão de títulos e graus universitários para o exercício de atividades acadêmicas nas instituicões universitárias da Região; 
Que a conformação de propostas regionais nessa área deve ser pautada pela preocupação constante em salvaguardar os padrões de qualidade vigentes em cada País e pela busca de mecanismos capazes de assimilar a dinâmica que caracteriza os sistemas educacionais dos Países da Região, que correspondem ao seu contínuo aperfeiçoamento,

Acordam:

\section{Artigo Primeiro}

Os Estados Partes, por meio de seus organismos competentes, admitirão, unicamente para o exercício de atividades de docência e pesquisa nas instituições de ensino superior no Brasil, nas universidades e institutos superiores no Paraguai, nas instituições universitárias na Argentina e no Uruguai, os títulos de graduação e de pós-graduação reconhecidos e credenciados nos Estados Partes, segundo procedimentos e critérios a serem estabelecidos para a implementação deste Acordo. (grifo nosso).

\section{Artigo Segundo}

Para os fins previstos no presente Acordo, consideram-se títulos de graduação aqueles obtidos em cursos com duração mínima de quatro anos e duas mil e setecentas horas cursadas, e títulos de pós-graduação tanto os cursos de especialização com carga horária presencial não inferior a trezentas e sessenta horas, quanto os graus acadêmicos de mestrado e doutorado.

\section{Artigo Terceiro}

Os títulos de graduação e pós-graduação referidos no artigo anterior deverão estar devidamente validados pela legislação vigente nos Estados
Partes. (grifo nosso).

O presente Acordo subtitui o Protocolo de Admissão de Títulos e Graus Universitários para o Exercício de Atividades Acadêmicas nos Estados Partes do MERCOSUL, assinado em 11 de junho de 1997, em Assunção, e seu Anexo firmado em 15 de dezembro de 1997, em Montevidéu.

Feito na cidade de Assunção, capital da República do Paraguai, aos quatorze dias do mês de junho do ano de mil novecentos e noventa e nove, em três originais no idioma espanhol e um no idioma português, sendo os textos igualmente autênticos ${ }^{7}$.

No caso brasileiro, seis anos após a assinatura do Acordo, e dentro dessa linha de raciocínio jurídico, o mesmo foi normatizado pelo Decreto Presidencial no. 5.518, de 23 de agosto de $2005^{8}$, oriundo do Decreto Legislativo $n^{\circ} .800$, de 23 de outubro de 2003.

E quando há a incorporação ao direito positivo interno de um tratado internacional, o mesmo ganha condão de lei ordinária, obtendo natureza jurídica e consequentemente, a sua efetividade e exequibilidade serão analisadas sob o crivo hierarquizado da Constituição Federal, ou seja, gera legitimidade no direito material e formal.

DECRETO No ${ }^{\circ}$. 5.518, DE 23 DE AGOSTO DE 2005.

\section{O PRESIDENTE DA REPÚBLICA,}

no uso da atribuição que lhe confere o art. 84, inciso IV, da Constituição, Considerando que o Congresso Nacional aprovou, por meio do Decreto Legislativo ${ }^{\circ}$. 800 , de 23 de outubro de 2003, o texto do Acordo de Admissão de Títulos e Graus Universitários para o Exercício de Atividades Acadêmicas nos Estados Partes do Mercosul, celebrado em Assunção em 14

${ }^{7}$ Acordo de Admissão de Títulos e Graus Universitários para o Exercício de Atividades Acadêmicas nos Estados Partes do Mercosul. Disponível em http://www2.mre.gov.br/dai/m_3415.htm.

8 . Decreto Presidencial n ${ }^{\circ}$. 5.518, de 23 de agosto de 2005. Promulga o Acordo de Admissão de Títulos e Graus Universitários para o Exercício de Atividades Acadêmicas nos Estados Partes do Mercosul. Disponível em: http://www.planalto.gov.br/ccivil_03/_Ato20042006/2005/Decreto/D5518.htm. Acesso em: 21 nov. 2011. 
de junho de 1999; Considerando que o Governo brasileiro depositou seu instrumento de ratificação em 21 de maio de 2004; Considerando que o referido Acordo entrou em vigor internacional e para o Brasil em 20 de junho de 2004;

\section{DECRETA:}

Art. $1^{\circ} \mathrm{O}$ Acordo de Admissão de Títulos e Graus Universitários para o Exercício de Atividades Acadêmicas nos Estados Partes do Mercosul, celebrado em Assunção em 14 de junho de 1999, apenso por cópia ao presente Decreto, será executado e cumprido tão inteiramente como nele se contém. (grifo nosso).

Art. $2^{\mathbf{0}}$ São sujeitos à aprovação do Congresso Nacional quaisquer atos que possam resultar em revisão do mencionado Acordo ou que acarretem encargos ou compromissos gravosos ao patrimônio nacional, nos termos do art. 49, inciso I, da Constituição.

Art. $3^{\circ}$ Este Decreto entra em vigor na data de sua publicação.

Brasília, 23 de agosto de 2005; $184^{\circ}$ da Independência e $117^{\circ}$ da República.

\section{LUIZ INÁCIO LULA DA SILVA}

Posteriormente, o Ministério da Educação, por meio da Secretaria de Educação Superior, expediu o ofício circular $n^{\circ}$. 152/2005 - MEC/SESu/ GAB, em 02 de dezembro de $2005^{9}$, comunicando o cumprimento de sua adesão ao acordo:

\section{Ofício Circular $n^{\circ}$ 152/2005 - MEC/ SESu/GAB}

Brasília - DF, 02 de dezembro de 2005.

\author{
Assunto: MERCOSUL - Entrada em \\ vigor do acordo de Admissão de Tí- \\ tulos e Graus Universitários para o \\ Exercício de Atividades Acadêmicas \\ nos Estados Partes do Mercosul.
}

Aos Senhores Dirigentes das Instituições de Ensino Superior - IES

Senhor Dirigente,

1. A Secretaria de Educação Superior do Ministério da Educação informa a Vossa Magnificência sobre a ratificação e incorporação ao ordenamento jurídico nacional do Acordo de Admissão de Títulos e Graus Universitários para o Exercício de Atividades Acadêmicas nos Estados Partes do MERCOSUL, por meio do Decreto Presidencial $\mathrm{n}^{\circ}$ 5.518, de 23 de agosto de 2005.

2. O referido Acordo trata da admissão automática de títulos e graus universitários dos Estados Partes do MERCOSUL para o exercício de atividades acadêmicas nas instituições definidas em seu Artigo Primeiro.

3. Encaminho anexo o texto do referido Acordo, para que se esclareçam todas as condições e ressalvas inerentes a este.

4. Enfatizo, principalmente, que o Acordo se refere à admissão de diplomas dos Estados Partes unicamente para o exercício de atividades de docência e pesquisas nas instituições de ensino superior. Para os demais casos, permanecem os procedimentos definidos na legislação vigente.

5. Peço a Vossa Magnificência que encaminhe o texto do referido Acordo aos departamentos competentes em sua Universidade, para conhecimento e providências que forem necessárias.

Atenciosamente,

Nelson Maculan

Secretário de Educação Superior/MEC

Entretanto e em atrito às legislações acima expostas, já se havia legislado acerca da 
matéria no Brasil, através da lei $\mathrm{n}^{\circ}$. 9.394, de 20 de dezembro de $1996^{10}$, a qual estabelecia as diretrizes e bases da educação nacional, em especial no seu artigo 48, onde há menção específica aos diplomas de mestrado e doutorado expedidos por universidades estrangeiras, exigindo expressamente a revalidação desses títulos por universidades brasileiras:

Lei no. 9394, de 20 de dezembro de 1996. ...

Art. 48. Os diplomas de cursos superiores reconhecidos, quando registrados, terão validade nacional como prova da formação recebida por seu titular.

$\S \mathbf{1}^{\mathbf{0}}$ Os diplomas expedidos pelas universidades serão por elas próprias registrados, e aqueles conferidos por instituições não universitárias serão registrados em universidades indicadas pelo Conselho Nacional de Educação.

$\S 2^{\circ}$ Os diplomas de graduação expedidos por universidades estrangeiras serão revalidados por universidades públicas que tenham curso do mesmo nível e área ou equivalente, respeitando-se os acordos internacionais de reciprocidade ou equiparação.

$\S 3^{\circ}$ Os diplomas de Mestrado e de Doutorado expedidos por universidades estrangeiras só poderão ser reconhecidos por universidades que possuam cursos de pós-graduação reconhecidos e avaliados, na mesma área de conhecimento e em nível equivalente ou superior.

Todavia, a legislação supra é anterior ao Acordo Internacional assinado em 1999, razão pela qual não tem força para revogar as disposições conferidas naquele documento, por ser uma questão de ordem pública interna e obediência às regras de hierarquia das leis, as quais a seguir serão abordadas.

\section{Questão de Ordem Pública Interna: Norma jurídica estrangeira}

Para compreender melhor a dinâmica do ordenamento jurídico brasileiro em vigor, deve-se observar, dentro do conjunto de leis, a sua hierarquia normativa legal, conforme quadro abaixo.

\section{HIERARQUIA DAS NORMAS LEGAIS}

Leis Constitucionais

Leis Complementares

Leis Ordinárias e Delegadas

- Decretos Legislativos

Constituições Estaduais

Leis Estaduais

Leis Orgânicas

Leis Municipais

Normas subalternas - resoluções; portarias; instruções, entre outras.

Conforme se verifica pela análise do quadro acima, a primeira norma que surge hierarquicamente é a norma constitucional. Em segundo plano, as Leis Complementares, Leis Ordinárias, Delegadas e Decretos Legislativos e, por fim, demais normas infraconstitucionais. No presente caso, a norma infraconstitucional mencionada é o "Decreto $\mathrm{n}^{\circ}$. 5.518, de 23 de Agosto de 2005" e o "Decreto Legislativo no. 800 , de 23 de outubro de 2003". Isso significa dizer que ambos estão situados na seara federal, ou seja, tem validade em todo território nacional.

Na hipótese do diplomado se sentir prejudicado pelo não reconhecimento do título, por exemplo, poderá se utilizar da lei brasileira ou poderá ainda valer-se de reclamação contra o País, conforme previsão constante do próprio 
Tratado Internacional, conforme nos ensina Caminha (2011) ${ }^{11}$, a seguir in verbis:

Paralelamente, sem prejuízo do ajuizamento da ação, cabe a reclamação contra o País, no âmbito internacional, seguindose os procedimentos previstos nos acordos internacionais que abranjam a hipótese do portador do título e, subsidiariamente, os demais mecanismos previstos pelo Direito Internacional Público [25]. A propósito disso, o "artigo 8" do "Protocolo de Integração Educacional para Prosseguimento de Estudos de Pós-Graduação nas Universidades dos Países membros do MERCOSUL" estabelece que: "1. As controvérsias que surjam, entre os Estados Partes, em decorrência da aplicação, interpretação ou do não cumprimento das disposições contidas no presente Protocolo serão resolvidas mediante negociações diplomáticas diretas. 2. Se, mediante tais negociações, não se alcançar um acordo ou se a controvérsia for solucionada apenas em parte, serão aplicados os procedimentos previstos no Sistema de Solução de Controvérsias vigente entre os Estados Partes do Tratado de Assunção". No "Acordo de Admissão de Títulos e Graus Universitários para o Exercício de Atividades Acadêmicas nos Estados-Partes do Mercosul", aprovado pelo Decreto Legislativo $\mathrm{n}^{\circ}$. 800/2003, não consta disposição semelhante, todavia, como faz parte do Tratado de Assunção, a ele se aplica a mesma sistemática descrita, de solução de controvérsias.

\section{Problematização}

\begin{abstract}
"Os professores são profissionais mais importantes do que os psiquiatras e os juízes. Lavram os solos da inteligência dos alunos para que não adoeçam e não sejam tratados pelos psiquiatras, para que não cometam crimes e não sejam julgados pelos juízes".
\end{abstract}

Augusto Cury
Como já informado, a problematização da questão legal consiste no fato de que acadêmicos brasileiros que tenham concluído o curso de mestrado e/ou doutorado em universidade estrangeira de países membros do MERCOSUL, possam ter seu título reconhecido automaticamente no Brasil. Segundo a Coordenação de Aperfeiçoamento de Pessoal de Nível Superior, a CAPES, responsável pela expansão e consolidação da pós-graduação stricto sensu (mestrado e doutorado) em todos os Estados da Federação, os diplomas expedidos pelas universidades estrangeiras, precisam ser validados, "em tese" (revalidados), de acordo com a previsão do art. 48 da Lei no. 9.394/1996 - Lei de Diretrizes e Bases da Educação Nacional.

Desta forma, a situação jurídica dos diplomas de mestrado e doutorado numa abordagem jurisprudencial, mostra as vertentes positivadas do direito pátrio nacional e nesta linha de pensamento, trouxemos 02 (dois) julgados antagônicos, na intenção de provocar a discussão acadêmica e assim, chegar à formação conceitual de uma linha própria alicerçada no direito positivado.

\subsection{A discussão de efeito positivo da CAPES:}

REVALIDAÇÃO. DIPLOMA. MESTRADO. MERCOSUL.

Trata-se de professor universitário auxiliar que, para galgar progressão funcional como professor assistente, busca judicialmente o reconhecimento do curso de mestrado concluído no Paraguai a fim de que o diploma seja aceito com admissão automática, sem os ritos de revalidação previstos na Lei n. 9.394/1996 (Lei de Diretrizes e Bases da Educação Nacional-LDB). Para isso, alega o recorrente a existência de tratado internacional - Acordo de Admissão de Títulos e Graus Universitários para o Exercício de Atividades Acadêmicas nos Estados Partes do Mercosul-, o qual, a seu ver, prevê o uso automático de títulos acadêmicos expedidos nos países signatários, com força de lei, visto ter sua aprovação no Dec. Legislativo 
n. 800/2003 e promulgação com o Dec.

Presidencial n. 5.518/2005. O tribunal a quo considerou que os termos do tratado internacional não afastam as disposições legais vigentes previstas no art. 48 da Lei n. 9.394/1996, que impõe os trâmites para a revalidação do diploma adquirido em outro país. Por outro lado, o Conselho Nacional de Educação (órgão do Ministério da Educação), ao analisar semelhante questão, concluiu, em parecer, que a obtenção do título universitário ou de pós-graduação por brasileiros nos Estados partes do Mercosul não é automática e exige obediência ao processo de revalidação conforme a legislação vigente (LDB). No mesmo sentido, posiciona-se a doutrina, e a Segunda Turma já se pronunciou, entendendo também que o tratado internacional amolda-se ao ordenamento pátrio e demanda a revalidação. Diante do exposto, a Turma negou provimento ao recurso. Precedente citado: REsp 971.962-RS， DJe 13/3/2009. REsp 1.182.993-PR, Rel. Min. Humberto Martins, julgado em 3/5/2011 ${ }^{12}$.

$\mathrm{Na}$ outra extremidade, temos o entendimento jurisprudencial mais harmonioso com o espírito de integração do MERCOSUL, segundo o qual mestres e doutores de universidades estrangeiras em territórios de Estados Partes - em especial os que vivem no Brasil - não têm a necessidade de promover a revalidação de seus diplomas, acolhendo-se a admissão automática, por força da legislação vigente.

\subsection{A discussão de efeito negativo da CAPES:}

Os Tratados Internacionais incorporados ao nosso ordenamento jurídico guardam relação de paridade normativa com as leis ordinárias, no que se refere à validade, eficácia e autoridade (ADI 1.480 MC/DF, DJ 18/05/01, rel.
Min. Celso de Mello) ${ }^{13}$, sendo princípio básico de hermenêutica que, quando uma lei faz remissão a dispositivos de outra norma da mesma hierarquia, estes se incluem na compreensão daquela, passando a constituir parte integrante do seu conceito (art. $2^{\circ}$ da LICC e STJ - RT 720/289), resta evidente que $o$ art. $48, \S 3^{\circ}$, da LDB, enquanto lei ordinária que exigia reconhecimento de qualquer diploma estrangeiro para emprestar-lhe validade no Brasil, se acha modificado pela norma posterior - o Acordo Internacional. Dessa forma é que se tem entendido que os diplomas obtidos nos países do MERCOSUL têm validade automática no Brasil, se destinados aos fins acadêmicos de docência ou pesquisa.

ADI 1480 / DF - DISTRITO FEDERAL AÇÃO DIRETA DE INCONSTITUCIONALIDADE

Relator(a): Min. CELSO DE MELLO

Julgamento: 26/06/2001

DECISÃO: Trata-se de ação direta de inconstitucionalidade, ajuizada com o objetivo de questionar a validade jurídico-constitucional do Decreto Legislativo $n^{0} .68 / 92$, que aprovou a Convenção $n^{0} .158$ da Organização Internacional do Trabalho (O.I.T.), e do Decreto $\mathbf{n}^{0}$. $1.855 / 96$, que promulgou esse mesmo ato de direito internacional público.

[...] PROCEDIMENTO CONSTITUCIONAL DE INCORPORAÇÃO DOS TRATADOS OU CONVENÇÕES INTERNACIONAIS. É na Constituição da República - e não na controvérsia doutrinária que antagoniza monistas e dualistas - que se deve buscar a solução normativa para a questão da incorporação dos atos internacionais ao sistema de direito positivo interno brasileiro. $O$ exame da vigente Constituição Federal permite constatar que a execução dos tratados internacionais e a sua incorpo-

\footnotetext{
${ }^{12}$ Instituto Sul-Americano de Pesquisa e Desenvolvimento. Decisão do Ministro do STJ Humberto Martins: Revalidação. Diploma. Mestrado. Mercosul. Disponível em: <http://www.isped.com.br/site/conteudo/noticias/055.htm>. Acesso em: 21 nov. 2011.

13 . Supremo Tribunal Federal. Medida Cautelar na Ação Direta de Inconstitucionalidade. Disponível em: $<$ http://www.stf.jus.br/ portal/jurisprudencia/listarJurisprudencia.asp?s1=\%28ADI $\% 24 \% 2 \mathrm{ESCLA} \% 2 \mathrm{E}+\mathrm{E}+1480 \% 2 \mathrm{ENUME} \% 2 \mathrm{E} \% 29+\mathrm{OU}+\% 28 \mathrm{ADI} \% 2 \mathrm{EACMS} \% 2$ $\mathrm{E}+\mathrm{ADJ} 2+1480 \% 2 \mathrm{EACMS} \% 2 \mathrm{E} \% 29 \&$ base=baseAcordaos>. Acesso em: 21 nov. 2011.
} 
ração à ordem jurídica interna decorrem, no sistema adotado pelo Brasil, de um ato subjetivamente complexo, resultante da conjugação de duas vontades homogêneas: a do Congresso Nacional, que resolve, definitivamente, mediante decreto legislativo, sobre tratados, acordos ou atos internacionais (CF, art. 49, I) e a do Presidente da República, que, além de poder celebrar esses atos de direito internacional (CF, art. 84, VIII), também dispõe - enquanto Chefe de Estado que é - da competência para promulgá-los mediante decreto. $\mathrm{O}$ item procedimental de incorporação dos tratados internacionais - superadas as fases prévias da celebração da convenção internacional, de sua aprovação congressional e da ratificação pelo Chefe de Estado - conclui-se com a expedição, pelo Presidente da República, de decreto, de cuja edição derivam três efeitos básicos que lhe são inerentes: (a) a promulgação do tratado internacional; (b) a publicação oficial de seu texto; e (c) a executoriedade do ato internacional, que passa, então, e somente então, a vincular e a obrigar no plano do direito positivo interno. Precedentes ${ }^{14}$.

Em que pese, data vênia, a argumentação exarada nos processos citados acima, nosso posicionamento é distinto, pois entendemos que o indivíduo detentor do título de graduação ou de pósgraduação, obtido em instituição de Estado Parte do MERCOSUL, pode se utilizar do mesmo de maneira automática para efeitos de exercer atividade de docência. Ressalte-se ainda, que essa linha de pensamento já encontrava suporte no ordenamento jurídico nacional, através do Protocolo de Integração Educacional para Prosseguimento de Estudos de Pós-Graduação nas Universidades dos Países Membros do MERCOSUL, aprovado pelo Decreto Legislativo $n^{\circ}$. 33, de 7 de Junho de 1999 e promulgado pelo Decreto $n^{\circ} .3 .196$, de 5 de Outubro de 1999.

Numa tentativa de acabar com a polêmica, em 08 de dezembro de 2009, em Montevidéu, e acatando uma solicitação da CAPES, o Conselho do Mercado Comum se reuniu e proferiu “decisão" (MERCOSUL/CMC/DEC. No. 29/09), estipulando o seguinte:

MERCOSUL/CMC/DEC. No. 29/09. $\ldots$

Artigo $5^{\circ}$

Do Fomento ao Intercâmbio

Os Estados Partes promoverão o intercâmbio acadêmico e científico. Para tanto, informarão anualmente a disponibilidade de programas de fomento, por meios dos órgãos competentes do Setor Educacional do MERCOSUL. (grifo nosso).

O documento, uma decisão inferior a qualquer tratado ou lei, menciona ainda, a necessidade de incorporar seu conteúdo ao ordenamento jurídico interno antes de setembro de 2010, o que não aconteceu até o presente momento, bem como estipula a criação de novas regras sobre o assunto no futuro. Tal decisão deixa absolutamente clara e evidente a posição de que os títulos do MERCOSUL, para ter validade no Brasil, devem ser revalidados formalmente pelas universidades brasileiras. Entretanto, sob a ótica jurídica, não pode prevalecer frente às normas concebidas em um Tratado Internacional, pelo que o instrumento utilizado para tratar do assunto, uma simples decisão do conselho, não tem força derrogatória ao dispositivo anteriormente legislado.

Nas palavras de (MIRANDA JUNIOR) ${ }^{15}$, “o Acordo para Admissão de Títulos e Graus Universitários foi firmado com o status de tratado internacional e já estava regularmente inserido no ordenamento jurídico brasileiro e não era mesmo crível que uma "Decisão" de um órgão inferior viesse pôr em dúvida as relações jurídicas de Direito Público Internacional do país ou tivesse o condão de rever a vontade política do povo brasileiro, identificada nos atos legais do Chefe da Nação e do Congresso Nacional. Como sabemos, o mecanismo de controle para inserção de normas e acordos internacionais não pode ser encurtado e nem se dá mediante atalhos. Como a pretensa al-

${ }^{14}$ _. Supremo Tribunal Federal. Ação Direta de Inconstitucionalidade. Disponível em: <http://www.stf.jus.br/portal/processo/ verProcessoAndamento.asp?incidente=1646696>. Acesso em: 21 nov. 2011.

${ }^{15}$ MIRANDA JUNIOR, J.J. Entenda como funciona a validação dos diplomas estrangeiros no Brasil, disponível em http://www.esjus.com.br/ entenda-como-funciona-a-validacao-dos-diplomas-estrangeiros-no-brasil; 
teração não passou pelos canais próprios, do Poder Legislativo e do Executivo nacional, nosso modesto entendimento sempre foi que os diplomas de mestre e doutor obtidos validamente nos Estados Partes firmatários do Acordo em questão continuam admitidos e plenamente válidos no Brasil, sem a necessidade de qualquer procedimento de reconhecimento ou revalidação - unicamente para as atividades de docência e pesquisa nas IES.”

\section{Conclusão}

Do ponto de vista do direito positivado interno brasileiro, o título obtido em instituição de ensino superior do MERCOSUL, hoje, possui o mesmo valor e legalidade que o conquistado no território nacional. Produz todos os seus efeitos legais, de eficácia e validade, também em todos os países associados ao MERCOSUL e de forma automática, para efeito da prática de atividades docentes e de pesquisa, sem a necessidade, portanto, de ser submetido ao procedimento de revalidação, conforme hipótese do art. 48 da Lei no ${ }^{\circ}$ 9.394, de 20 de dezembro de 1996 - Lei de Diretrizes e Bases da Educação Nacional.

Corroborando esse entendimento, as adesões internacionais do estado brasileiro são direitos sociais fundamentais previstos na nossa Carta Constitucional - parágrafos $1^{\circ} \mathrm{e} 2^{\circ}$ do art. $5^{\circ} \mathrm{e}$ art. $6^{\circ}$, o que significa dizer ser a sua aplicabilidade imediata. Uma vez integrada às normas jurídicas do Tratado do MERCOSUL (Decreto Legislativo $\mathrm{n}^{\circ} .800$, de 23 de outubro de 2003, com o Decreto Presidencial no. 5.518, de 23 de agosto de 2005), essas, se encontram em paridade normativa com as leis ordinárias brasileiras.

Não somos refratários ao empenho do Brasil ou de qualquer outro Estado membro do MERCOSUL na busca pela qualidade e excelência acadêmica de docentes e pesquisadores, nacionais ou estrangeiros. Também não aceitamos a criação de atalhos ou fórmulas encantadas para que se possa usufruir dos títulos acadêmicos conquistados, em sua grande maioria, frise-se, com árduo esforço e dedicação incondicional.
Porém, ao analisar com certa profundidade a questão, não se pode deixar de refletir acerca do cenário jurídico atual e os direitos aqui envolvidos e se, efetivamente, o estado brasileiro cumpre sua parte no que concerne ao seu comprometimento com os acordos internacionais firmados e com a legislação interna que ele próprio conduziu. De certo que a questão está longe de uma solução definitiva e o que esse texto pretende é justamente impulsionar a discussão do tema demonstrando as vertentes doutrinárias legais a respeito do assunto e os aspectos jurídicos que o envolvem. Diante desse impasse fica $o$ alerta, no sentido de orientar os futuros alunos sobre os aspectos positivos e negativos vinculados à opção de cursar Mestrados e Doutorados nos países integrantes do MERCOSUL.

Por todo o exposto, permanece imaculada na nossa percepção, a esperança de que um dia e em nome de uma América Latina mais integrada, forte e unida, a legislação pátria prevaleça na função harmoniosa de que a comunidade acadêmica possa ver reconhecida de forma rápida e direta, os seus respectivos títulos mercosulenses em sua terra pátria.

\section{Referências Bibliográficas}

1. ARAÚJO, Luiz Alberto David. Curso de direito constitucional / Luiz Alberto David Araújo, Vidal Serrano Nunes Junior. 12. ed. rev. e atual. São Paulo: Saraiva, 2008.

2. BANDEIRA DE MELLO, Celso Antônio. Conteúdo jurídico do princípio da igualdade. 3. ${ }^{\mathrm{a}}$ ed. São Paulo: Malheiros Editores, 2006.

3. BARRUFFINI, José Carlos Tosetti. Direito constitucional. 2. ${ }^{a}$ ed. São Paulo: Saraiva, 2007.

4. BOBBIO, Norberto. Teoria do ordenamento jurídico. $10^{\mathrm{a}}$ ed. Editora Universidade de Brasília. Brasília. 2006.

5. BRASIL.Constituição(1988).Constituição da República Federativa do Brasil. 41. ed. atual. e ampl. São Paulo: Saraiva. 2008.

${ }^{15}$ MIRANDA JUNIOR, J.J. Entenda como funciona a validação dos diplomas estrangeiros no Brasil, disponível em http://www.esjus.com.br/ entenda-como-funciona-a-validacao-dos-diplomas-estrangeiros-no-brasil; 
6. CINTRA, Antônio Carlos de Araújo, Grinover, Ada Pelegrini, Dinamarco, Cândido Rangel. Teoria geral do processo. 24. ${ }^{\mathrm{a}}$ ed. São Paulo: Malheiros Editores, 2008.

7. CURY, Augusto. O código da inteligência: a formação de mentes brilhantes e a busca pela excelência emocional e profissional. Rio de Janeiro: Thomas Nelson Brasil/Ediouro, 2008.

8. ESPÍNDOLA, Samuel Ruy. Conceito de princípios constitucionais, 2. ${ }^{\mathrm{a}}$ ed. São Paulo: Editora Revistas dos Tribunais, 2002.

9. FRAUCHES, Celso da Costa. Fagundes, Gustavo M. LDB anotada e comentada, Brasília: Ilape, 2003.

10. NADER, Paulo. Introdução ao estudo do direito. 28. a ed. Rio de Janeiro: Editora Forense, 2007.

11. RAMPAZZO,Lino. Metodologia científica. 3. ${ }^{\text {a }}$ ed. São Paulo: Edições Loyola, 2002.

12. SECCO, Orlando de Almeida. Introdução ao estudo do direito. 10. ${ }^{a}$ ed. São Paulo: Lumen Juris, 2007.

13. SERRANO, Pablo Jiménez. Interpretação jurídica: OMétodo Lógico de Interpretação do Direito e suas Normas. 1. ${ }^{\text {a }}$ ed. São Paulo: Desafio Cultural, 2002.

14. SILVA, De Plácido e. Vocabulário jurídico. 20. ed. 3. tir. Rio de Janeiro: Forense, 2002.

15. TEMER, Michel. Elementos de direito constitucional. 22. ${ }^{\text {a }}$ ed. São Paulo: Malheiros Editores, 2007.

16. BULHÕES, Alcides Emanoel Espíndola. Tratados internacionais e sua eficácia jurídica no ordenamento jurídico brasileiro. Disponível em:http://www. periodicoedireito.com.br/index. php?option $=$ com_content $\&$ task $=\mathrm{vi}$ ew\&id=727\&Itemid=39. Acesso em: 21 nov. 2011.
17. CAMINHA, Marco Aurélio Lustosa. Revalidação de títulos de pós-graduação obtidos em universidades estrangeiras. Disponívelem: $<$ http://jus.uol.com.br/revista/ texto/4372. Acesso em: 21 nov. 2011.

18. . Decreto ${ }^{\circ}$. 6.374, de 18 de fevereiro de 2008. Dispõe sobre a execução do qüinquagésimo nono protocolo adicional ao acordo de complementação econômica $n^{0}$. 18, entre os Governos da República Argentina, da República Federativa do Brasil, da República do Paraguai e da República Oriental do Uruguai, relativo a transações comerciais em moedas locais. Disponível em: http://www.planalto.gov. br/ccivil_03/_Ato20072010/2008/Decreto/ D6374.htm. Acesso em: 21 nov. 2011.

19. dezembro de 2009. Promulga a Convenção de Viena sobre o Direito dos Tratados, concluída em 23 de maio de 1969, com reserva aos Artigos 25 e 66. Disponível em: http:/www.planalto.gov.br/ccivil_03/_ Ato20072010/2009/Decreto/D7030.htm. Acesso em: 21 nov. 2011.

20. Decreto Legislativo $n^{\circ}$. 66, de 16 de novembro de 1981. Aprova o texto do Tratado de Montevidéu 1980, firmado pelos Plenipotenciários dos Governos da República Federativa do Brasil, da República Argentina, da República da Bolívia, da República da Colômbia, da República do Chile, da República do Equador, dos Estados Unidos Mexicanos, da República do Paraguai, da República do Peru, da República Oriental do Uruguai, e da República da Venezuela, a 12 de agosto de 1980. Disponível em: http://www.diariodasleis.com.br/busca/ exibelink.php?numlink=1-98-17-1981-1116-66 . Acesso em: 21 nov. 2011. 
21. . Decreto Presidencial $n^{\circ}$. 5.518, de 23 de agosto de 2005. Promulga o Acordo de Admissão de Títulos e Graus Universitários para o Exercício de Atividades Acadêmicas nos Estados Partes do Mercosul. Disponível em: http://www.planalto.gov.br/ccivil_03/ Ato2004-2006/2005/Decreto/D5518.htm. Acesso em: 21 nov. 2011.

22. Decreto Presidencial n ${ }^{\circ} .87 .054$, de 23 de março de 1982. Promulga o Tratado de Montevidéu 1980. Disponível em: http:// www2.mre.gov.br/dai/m_87054_1980. htm . Acesso em: 21 nov. 2011.

23. FILHO, Reinaldo de Souza Couto. Considerações sobre a validade, a vigência e a eficácia das normas jurídicas. Disponível em:http://jus.uol.com.br/revista/ texto/21. Acesso em: 21 nov. 2011.

24. INSTITUTO Sul-Americano de Pesquisa e Desenvolvimento. Decisão do Ministro do STJ Humberto Martins: Revalidação. Diploma. Mestrado. Mercosul. Disponível em: http://www. isped.com.br/site/conteudo/noticias/055. htm. Acesso em: 21 nov. 2011.

25. Lei $n^{\circ}$. 9.394, de 20 de dezembro de 1996. Estabelece as diretrizes e bases da educação nacional. Disponível em: https://www.planalto.gov.br/ccivil_03/ Leis/L9394.htm. Acesso em: 21 nov. 2011.

26. Lei Complementar $\mathrm{n}^{\circ}$. 95, de 26 de fevereiro de 1998. Dispõe sobre a elaboração, a redação, a alteração e a consolidação das leis, conforme determina o parágrafo único do art. 59 da Constituição Federal, e estabelece normas para a consolidação dos atos normativos que menciona. Disponível em: http://www. planalto.gov.br/ccivil_03/Leis/LCP/Lcp95. htm . Acesso em: 21 nov. 2011.

27. Ministério da Educação. Secretaria de Educação Superior. Ofício Circular $n^{\circ}$ 152/2005 - MEC/SESu/GAB. Assunto: MERCOSUL - Entrada em vigor do acordo de Admissão de Títulos e Graus
Universitários para o Exercício de Atividades Acadêmicas nos Estados Partes do Mercosul. Disponível em: http://www. postgradosparaguay.com/pdf/oficio_MEC_ num_152-05.pdf. Acesso em: 21 nov. 2011.

28. MIRANDA JUNIOR, J.J.. Entenda como funcionaa validação dos diplomas estrangeiros no Brasil, disponível em http://www.esjus. com.br/entenda-como-funciona-a-validacaodos-diplomas-estrangeiros-no-brasil;

29. MORE, Rodrigo Fernandes. Aplicação e execução de tratados internacionais no Brasil. Disponível em: http://jus.uol.com.br/ revista/texto/8517. Acesso em: 21 nov. 2011.

30.

Ação Direta de Inconstitucionalidade. Disponível em: http://www.stf.jus.br/ portal/processo/verProcessoAndamento. asp? incidente $=1646696$. Acesso em: 21 nov. 2011.

31.

Medida Cautelar na Aç̃o Direta de Inconstitucionalidade. Disponível em:http://www.stf.jus.br/portal/ jurisprudencia/listarJurisprudencia.asp?s $1=\% 28$ ADI $\% 24 \% 2 \mathrm{ESCLA} \% 2 \mathrm{E}+\mathrm{E}+148$ $0 \% 2 \mathrm{ENUME} \% 2 \mathrm{E} \% 29+\mathrm{OU}+\% 28 \mathrm{ADI} \%$ $2 \mathrm{EACMS} \% 2 \mathrm{E}+\mathrm{ADJ} 2+1480 \% 2 \mathrm{EACMS}$ $\% 2 \mathrm{E} \% 29 \&$ base $=$ baseAcordaos. Acesso em: 21 nov. 2011.

32. VIENNA, Convention on the Law of Treaties, 01/27/80, disponível em http:// untreaty.un.org/ilc/texts/instruments/english/conventions/1_1_1969.pdf.

\author{
Endereço para Correspondência: \\ Marcos Machado \\ marcosmachado001@hotmail.com \\ Centro Universitário de Volta Redonda - UniFOA \\ Campus Universitário Olezio Galotti \\ Av. Paulo Erley Abrantes, 1325 \\ Três Poços - Volta Redonda - RJ \\ CEP: $27.240-560$
}

Informacões bibliográficas:

Conforme a NBR 6023:2002 da Associaç̃o Brasileira de Normas Técnicas (ABNT), este texto científico publicado em periódico eletrônico deve ser citado da seguinte forma: MACHADO, Marcos; FONTES, Mario Arthur de Souza; NETO, Dario Aragão. Legalidade e Eficácia Jurídica dos Títulos de Pós-Graduação Stricto Sensu - Mestrado e/ou Doutorado - Originários dos Estados Partes do Mercosul, na Jurisdição Brasileira. Cadernos UniFOA. Volta Redonda, Ano VI, n. 17, dezembro 2011. Disponível em: <http://www. unifoa.edu.br/cadernos/edicao/17/59.pdf> 